\title{
Investigation of concrete crack repair by electrochemical deposition
}

\author{
Lifang Liu ${ }^{1, *}$, Bo Dong ${ }^{2}$ \\ ${ }^{1}$ School of Architectural Engineering, Ningbo Polytechnic, Ningbo 315800, Zhejiang, China \\ ${ }^{2}$ School of Architectural Engineering, Chuzhou Vocational and Technical College, Chuzhou 239000, \\ China \\ *E-mail: liullfyra@163.com
}

Received: 24 August 2021 / Accepted: 23 September 2021 / Published: 10 November 2021

\begin{abstract}
Cracks in reinforced concrete structures are inevitable in the process of use. Cracks not only affect the aesthetics of the structure appearance, but also affect the overall performance of the structure and shorten its life. Traditional methods are limited for repairing cracks in reinforced concrete in an aqueous environment. Electrochemical deposition is a relatively new method for repairing cracks in reinforced concrete, which fills and heals cracks in concrete, and increases the alkalinity of the surroundings of the reinforcing steel in concrete, slowing down the reinforcing steel corrosion caused by harmful substances. In this study, the changes in the surface coverage of the concrete specimens during the repair process were studied. Three different concentrations of electrolyte solutions were tested with three different intensities of electric current. The test results showed that the surface coverage of the concrete specimens was increasing during the repair process. The repair depths of the cracks on the specimens were measured by three different intensities of electric current to three different concentrations of electrolyte solutions at different times. The results showed that the repair rate of the crack depth of the specimens increased and then decreased with the increase of the current intensity. It can be concluded that the rate of crack repair increases with the current intensity and then decreases with the increase of electrolyte solution concentration.
\end{abstract}

Keywords: Crack repair; Electrochemical Deposition; Concrete; Mass change; Surface coverage

\section{$\underline{\text { FULL TEXT }}$}

(C) 2021 The Authors. Published by ESG (www.electrochemsci.org). This article is an open access article distributed under the terms and conditions of the Creative Commons Attribution license (http://creativecommons.org/licenses/by/4.0/). 